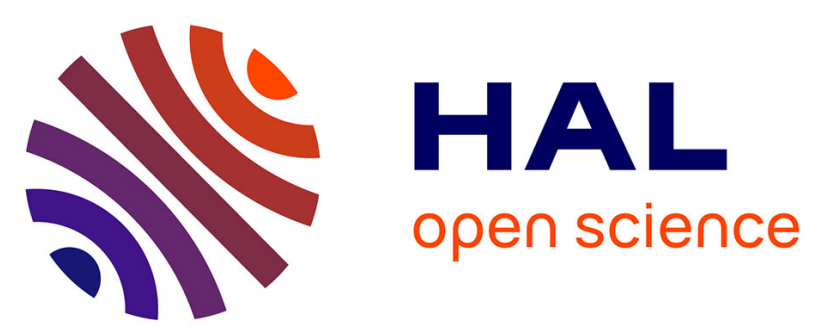

\title{
Model cheese aroma perception is explained not only by in vivo aroma release but also by salivary composition and oral processing parameters
}

\author{
Elizabeth Guichard, Marie Repoux, E.M. Qannari, Hélène Labouré, Gilles
} Feron

\section{To cite this version:}

Elizabeth Guichard, Marie Repoux, E.M. Qannari, Hélène Labouré, Gilles Feron. Model cheese aroma perception is explained not only by in vivo aroma release but also by salivary composition and oral processing parameters. Food and Function, 2017, 8 (2), pp.615-628. 10.1039/C6FO01472K . hal01564771

\author{
HAL Id: hal-01564771 \\ https://u-bourgogne.hal.science/hal-01564771
}

Submitted on 22 Feb 2018

HAL is a multi-disciplinary open access archive for the deposit and dissemination of scientific research documents, whether they are published or not. The documents may come from teaching and research institutions in France or abroad, or from public or private research centers.
L'archive ouverte pluridisciplinaire HAL, est destinée au dépôt et à la diffusion de documents scientifiques de niveau recherche, publiés ou non, émanant des établissements d'enseignement et de recherche français ou étrangers, des laboratoires publics ou privés. 


\section{Model cheese aroma perception is not only explained by in vivo aroma}

\section{2 release but also by salivary composition and oral processing parameters}

3 E. Guichard, ${ }^{* a}$ M. Repoux ${ }^{a}$, E. M. Qannari, ${ }^{\text {b }}$ H. Laboure, ${ }^{a}$ and G. Feron, ${ }^{a}$

$4{ }^{a}$ UMR CSGA (Centre des Sciences du Goût et de l'Alimentation): INRA, CNRS, Université de Bourgogne Franche-Comte, 5 AgroSupDijon, F-21000 Dijon, France.

6 'bUNAM University, ONIRIS, USC "Sensometrics and Chemometrics Laboratory", Nantes, France.

$7 \quad{ }^{*}$ Corresponding author. E. Guichard : elisabeth.guichard@inra.fr

8

9 Abstract

The aim of the present paper was to determine, on four model cheeses differing in fat content and firmness consumed by fourteen well characterised subjects, the respective impacts of in vivo aroma release, bolus rheology, chewing activity, mouth coating and saliva composition on dynamic aroma perception. The originality of the approach was to consider all the parameters together and to be able to evaluate their relative contribution using multi-block partial least square (MB-PLS) regression. Fruity aroma perception of the more hydrophilic compound (ethyl propanoate) was related to its dynamic release parameters before swallowing whereas blue cheese aroma perception of the more hydrophobic compound (nonan2-one) was related to its dynamic release parameters after swallowing and was highly impacted by mouth coating. Moreover MB-PLS approach made it possible to evidence the combined effects of saliva composition and cross-modal interactions to understand why in some cases dynamic aroma perception could not be explained by dynamic in vivo aroma release data. Subjects with low sodium content in saliva perceived fruity aroma which is not congruent with saltiness as less intense and salt- congruent (blue cheese) aroma as more intense, which was explained by their higher sensitivity to salt. Subjects with a high lipolysis activity perceived fruity aroma which is not congruent to fat as less intense and fat-congruent (blue cheese) aroma as more intense, which should be explained by the link between lipolysis activity and fat sensitivity. These results could be considered for the reformulation of foods towards specific populations taking into account nutritional recommendations.

Key words: aroma perception, aroma release, cheese, bolus rheology, saliva composition, chewing behaviour 


\section{Introduction}

Aroma perception is an important aspect of food acceptability by consumers. However it is often very difficult to directly explain aroma perception during food consumption by the amount of aroma compounds in the food. One explanation is that aroma compounds have first to be released from the food matrix to the vapour phase in the buccal cavity then transferred into the nasal cavity via the velum to reach the olfactory receptors ${ }^{1}$. The partition of aroma compounds between the food matrix and the vapour phase depends on the affinity of aroma compounds for the macromolecules present in the food ${ }^{2}$ which can be determined by measuring the vapour/matrix partition coefficients of aroma compounds. These coefficients depend both on the physico-chemical properties of the aroma but also on the food matrix composition. As an example hydrophobic aroma compounds are more soluble in fat than in water and thus are better released in the vapour phase from products with a reduced fat content ${ }^{3}$. Proteins are able to form reversible or irreversible binding with aroma compounds which will impact aroma release in the vapour phase $e^{4,5}$. In case of irreversible binding such as the formation of Schiff base between amino groups of proteins and aldehydes ${ }^{6}$, the aroma compounds cannot be released in the vapour phase and thus cannot be perceived. In case of reversible binding the aroma perception is lowered ${ }^{7}$. The major effect of hydrocolloids is to increase food viscosity and thus decrease the transfer of aroma compounds from matrix to vapour ${ }^{8,9}$, however inclusion complexes are formed between amylose and specific aroma compounds which also impacts aroma perception ${ }^{10}$. During consumption, food is mixed with saliva and broken down during the masticatory step to form a swallowable bolus. During this step, aroma compounds are transferred from food to saliva before being released in the nasal cavity. This transfer of aroma compounds is highly dependent on food composition and texture but also on subject's physiology ${ }^{11}$. Thanks to the development of on line aroma release technologies, such as atmospheric pressure chemical ionisation (APCI-MS) $)^{12}$ or proton transfer reaction mass spectrometry $(\mathrm{PTR}-\mathrm{MS})^{13}$, it was possible to better understand the impact on dynamic in vivo aroma release of food matrix composition and structure $^{14,15}$ and of physiological parameters such as chewing, swallowing, saliva flow ${ }^{16,17}$. Concerning the impact of food matrix, increasing fat content results in a decrease in maximum intensity and overall in vivo aroma release together with an increase in aroma remanence as was observed in gelatin gels ${ }^{18}$, whey protein gels ${ }^{15}$ or model cheeses $^{19}$, which was explained by a lower solubility of hydrophobic aroma compounds in fat. Even if food rheology could explain chewing activity during consumption ${ }^{20}$, bolus properties and in-mouth bolus rheology better explain in vivo aroma release $\mathrm{e}^{21}$. The amount of cheese remaining in the mouth after swallowing has also been found important to explain in vivo aroma release. A higher amount of fat product remaining in the mouth leads to a lower release of the more hydrophobic compounds before swallowing due to their high affinity for the food bolus and to a longer aroma persistence in the breath ${ }^{16,22}$. The less hydrophobic compounds are less 
impacted by mouth coating but are more quickly released from firmer cheeses, due to a higher food breakdown ${ }^{16,}$

${ }^{17}$. When consuming solid foods, differences in chewing activities between subjects are responsible for differences in aroma release, an intense chewing work leads to a higher amount of aroma release ${ }^{17}$.

However despite the development of in vivo measurements, results in the literature in the field of dairy products showed that no clear relationship exists between in vivo aroma release and aroma perception due to the coexistence of physicochemical and cognitive mechanisms ${ }^{23}$. Cognitive mechanisms are due to cross-modal interactions which vary according to the type of texture ${ }^{24}$. In the case of semi-liquid foods such as yoghurts, an increase in viscosity induced a decrease in both aroma release and aroma perception ${ }^{25}$, whereas for solid cheeses aroma perception decreased with firmness without any noticeable difference in aroma release ${ }^{26}$. This finding was explained by the attention paid by the subjects to the texture perception which likely led to a decrease in the aroma perception. By delivering simultaneously different kinds of texture and different odorants, Bult et al. ${ }^{27}$ showed that the perceived aroma intensity was reduced with increasing viscosity when the odour was presented either ortho or retronasally. Moreover the perceived thickness was increased only when the odour was presented retronasally simulataneously with swallowing time. An adaptation phenomenon was also evidenced in gel candies as being responsible for the influence of taste and texture on aroma perception ${ }^{28}$, by comparing the in vivo aroma release curves and sensory time intensity curves which were recorded simultaneously. This study showed that time at maximum chewing activity came first followed by time at maximum in nose concentration then time at maximum perceived intensity. The time delays between release and perception increased when the product remained longer in the mouth. The difficulties to relate results from analytic and sensory approaches was also pointed out in brandies ${ }^{29}$ and explained by sensory interactions between fruity and woody aroma ${ }^{30}$. In coffee, the burnt sensory notes could be associated with pyrazines detected by in vivo PTR-MS analysis but the effect of adding sugar produced a change in aroma perception from burnt to caramel which could not be associated to any change in aroma composition ${ }^{31}$, confirming the existence of sweet-aroma interactions ${ }^{23}$. Odour-taste interaction basically depends on the capacity of the two stimuli to form an appropriate combination in a food product context (congruency) $^{32}$. Thus, odour-taste integrated perception highly depends on learned associations, the context in which the food is consumed and the consumer's previous experience ${ }^{33}$. In experimental situations, odour-taste interactions were found to be affected by the so-called dumping and halo effects ${ }^{34}$, which resulted from the tendency for sensory panellists to dump their sensations on several available scales (taste and/or odour). Moreover, in more complex cheese flavour mixtures, $\mathrm{NaCl}$, lactic acid, and aroma were found to be able to enhance cheese flavour intensity and to compensate each other towards cheese flavour intensity ${ }^{35}$, thus suggesting complex taste-taste and taste-aroma interactions involved in the overall cheese flavour. So far, no study has investigated cross-modal interactions using parameters related to oral physiology. 
During the last decade, saliva has gained more and more interest in the field of sensory science. Indeed, due to its role in oral clearance, bolus moisturizing and hydrolytic properties, saliva promotes the disintegration of the matrix and thus the release of palatable active substances during food consumption. For example the salivary flow rate influences aroma release ${ }^{36}$ by a dilution effect ${ }^{37}$. Salivary flow has also been positively associated with liking for fat $^{38}$. Moreover, amylase activity can modify the bolus rheological properties ${ }^{39}$ and thus modulates the perception of salt in starch-based matrices ${ }^{40}$. Even subject to controversy, lipase might be responsible for hydrolysis of food triglycerides and thus fat perception ${ }^{41,42}$. Finally the catalytic activity of saliva against some aroma compounds (e.g. esters, aldehydes) has been demonstrated in vivo and in vitro ${ }^{43-46}$ with consequences on aroma release and thus on perception. Saliva is also composed of small and large molecules that contribute to maintain a "salivary homeostasis" whose background level can regulate the dynamics of molecule release and thus their sensory impact (sensory or nutritional) ${ }^{47}$. For instance, it has been shown that a human subject with a high salivary sodium concentration is less sensitive to saltiness ${ }^{48}$.

A previous paper ${ }^{22}$ highlighted the role of bolus rheology and composition of stimulated saliva on aroma release from cheeses varying in fat content and firmness. The aim of the present paper is to better understand the physicochemical and physiological parameters which drive dynamic aroma perception. For that purpose, a group of fourteen subjects were selected as representative of those participating to our previous study in order to evaluate aroma perception as a function of time and to determine, on these well characterised subjects, the respective impacts of in vivo aroma release, bolus rheology, chewing activity, mouth coating and saliva composition on dynamic aroma perception.

\section{Experimental}

\section{Cheese products}

Four processed model cheeses were $u^{16} d^{16}$. They were composed of a mixture of cheddar, soft cheese, butter, melting salts, protein powder (casein), salt and water. Two levels of texture ( $\mathrm{S}=\mathrm{soft}, \mathrm{F}=\mathrm{firm}$ ) were obtained by varying the water content and two ratio of fat to dry matter, a low level at $25 \%$ for low fat cheeses (Iff and IfS) and a high level at $50 \%$ for high fat cheeses (hfF and hfS). The pH ranged from 5.27 to 5.55. The rheological properties of the cheeses were measured in a large deformation at a rotation of $0.01 \mathrm{rad}^{-\mathrm{s}^{-1}}$ for $240 \mathrm{~s}$ using a Haake Viscotester (VT550 - Thermo electron GmbH, Karlsruhe, Germany), as previously described ${ }^{16}$. The breakdown stress corresponds to the maximum strength necessary to cause cheese breakdown, with the lowest values for the softest cheese ( $8129 \pm 469$ Pa for IfS and $8022 \pm 1309$ Pa for hfS) and the highest values for the firmest cheese (15253 $\pm 1231 \mathrm{~Pa}$ for IfF and $15556 \pm 2307 \mathrm{~Pa}$ for hfF). The critical strain at breakdown corresponds to the maximum rotation angle required to cause breakdown, with the lowest values for cheeses 
119

120

121

122

123

124

125

126

127

128

129

130

131

132

133

134

135

136

137

138

139

140

141

142

143

144

145

146

147

148

149

with the highest fat content $(0.273 \pm 0.022 \mathrm{rad}$ for hfS and $0.348 \pm 0.061 \mathrm{rad}$ for hfF $)$, and the highest values for cheeses with the lowest fat content $(0.804 \pm 0.056 \mathrm{rad}$ for IfS and $0.836 \pm 0.036 \mathrm{rad}$ for IfF). Two aroma compounds were added during cheese production, a hydrophobic ketone, nonan-2-one (NO: $\log \mathrm{P}=2.9,6 \mathrm{mg} \cdot \mathrm{kg}^{-1}$ ) and a hydrophilic ester, ethyl propanoate (EP: $\left.\log \mathrm{P}=1.4,25 \mathrm{mg} \cdot \mathrm{kg}^{-1}\right)$.

\section{Subjects}

In a first step, 48 subjects ( 23 female and 25 males) were selected from a group of 100 volunteers based on their good dental and oral status, and on the repeatability of physiological parameters (salivary flow rate under resting and stimulated conditions, respiratory flux, salivary composition) ${ }^{16,20}$. They were characterised for their oral volume, saliva composition and flow, in vivo release measurement, chewing activity, bolus saliva content, bolus rheology and mouth coating. From this group of 48 subjects, a subgroup of fourteen subjects ( 6 females and 8 males, average age: 40 years \pm 9 ) was selected for the sensory analyses, on their ability to detect and recognise the two aroma notes. The subjects were not allowed to smoke, eat or drink starting at least one hour before the different test sessions. All the subjects were informed of the observational nature of this study. They gave their signed consent and received a financial compensation for their participation. The study protocol was submitted to an Ethics Committee and was approved on 17 April 2008 by the Comité de Protection des Personnes Est-1 $\left(\mathrm{N}^{\circ} 2008 / 15\right)$ and on 8 August 2008 by the Direction Générale de la Santé - France $\left(\mathrm{N}^{\circ}\right.$ DGS2008-0196).

Subjects were characterised for specific physiological parameters described in the following sections.

\section{Oral volume}

Oral volume was measured using an Eccovision ${ }^{\circledR}$ acoustic pharyngometer (Hood Laboratories, USA), as described previously ${ }^{49}$. This device consists of two microphones and a horn driver mounted on a wave tube and connected to a PCcompatible computer with signal conversion capabilities. The signal was converted into the surface change $\left(\mathrm{cm}^{2}\right)$ as a function of the length of the oral cavity $(\mathrm{cm})$. The subjects held the mouthpiece in their mouth with their teeth against the flange and their tongue in a low position. To prevent air leaks, which could cause measurement errors, the subjects placed their lips over the flange, sealing the mouthpiece. The subjects were instructed to breath with their nose during the experiment. Values are expressed in $\mathrm{cm}^{3}$ and correspond to the average of 10 measures.

\section{Saliva samples and flow}

Since our previous study ${ }^{22}$ highlighted that resting saliva poorly contributed to explaining aroma release whereas stimulated saliva significantly impacted in vivo aroma release from soft cheeses, only results obtained with stimulated saliva 
150

151

152

153

154

155

156

157

158

159

160

161

162

163

164

165

166

167

168

169

170

171

172

173

174

175

176

177

178

179

are taken into account in the present paper. Stimulated saliva was collected as previously described ${ }^{49}$. The subjects chewed a piece of Parafilm ${ }^{\mathrm{TM}}(0.5 \mathrm{~g} \pm 0.2 \mathrm{~g})$ for a period of $5 \mathrm{~min}$ and spit out the saliva every 30 seconds into a pre weighed cup over a period of 5 minutes. The cups were weighted and the salivary flow rates were expressed in $\mathrm{mL}^{\mathrm{min}}{ }^{-1}$. Immediately after collection, the saliva samples were standardized by a first step of centrifugation for $30 \mathrm{~min}$ at $15000-\mathrm{x} \mathrm{g}$ to remove bacteria and cellular debris. Thereafter the supernatants were stored at $-80^{\circ} \mathrm{C}$ to stop metabolism until subjected to biochemical analyses.

\section{Biochemical analyses of saliva samples}

Protein concentrations. Protein concentrations (Prot) were measured with a standard Quick Start Bradford protein assay (Bio-Rad, France) with bovine serum albumin as the calibration standard.

Enzyme activities. All enzyme activities were expressed in International Enzyme Activity Units (U) per ml of saliva. One $U$ is defined as the amount of enzyme that catalyses the conversion of 1 micromole of substrate per minute. The lipolytic (Lipolysis), proteolytic (Proteolysis), lysozymal (Lysozyme) and amylolytic (Amylase) activities were determined as previously described $^{42,50,51}$.

Sodium analysis. The saliva samples were diluted to $1 / 20(50 \mu \mathrm{L}$ saliva in $950 \mu \mathrm{L}$ filtered $18 \mathrm{~m} \Omega$ Milli-Q-water (Millipore, Bedford, MA, USA)) and filtered through a membrane (pore size $=0.45 \mu \mathrm{m}$, C.I.L., Sainte-Foy-La-Grande, France). The amounts of sodium ( $\mathrm{Na}$ ) in saliva were determined by HPLC ionic chromatography using a Dionex ICS2500 ion chromatographic system (Dionex, Voisins le Bretonneux, France) as previously described ${ }^{52}$. Quantifications were performed using calibration curves realised with sodium standard solutions ranging from 0.1 to $10 \mathrm{mM}$ in $22 \mathrm{mM}$ sulfuric acid $\left(R^{2}=0.999\right)$.

\section{Sensory analyses}

All sessions took place in an air-conditioned $\left(21 \pm 2^{\circ} \mathrm{C}\right)$ sensory testing room of the ChemoSens platform (Centre des Sciences du Goût et de l'Alimentation, INRA, Dijon) using standardized booths equipped with computers. Subjects were instructed to place each piece of cheese $(6 \mathrm{~g})$ in the mouth, and freely consume it while keeping the lips closed. The products were presented in a random order at $17^{\circ} \mathrm{C}$. All measurements were done in triplicate. Bread, apple and water were used as mouth cleansers between two tests.

The subjects were firstly trained during eight sessions to recognise the odour of the two aroma compounds, blue cheese for nonan-2-one (NO) and fruity for ethyl propanoate (EP), using triangular tests and recognition tests. Other training sessions were conducted to familiarize the subjects with the discontinuous time-intensity methodology used. The last training 
180

181

182

183

184

185

186

187

188

189

190

191

192

193

194

195

196

197

198

199

200

201

202

203

204

205

206

207

208

209

sessions were dedicated to the use of a continuous scale ( 0 to 10 ) to score the intensity of the two aroma compounds. Two

test sessions were then done using Fizz $\mathbb{B}$ software to score the intensity of the two aroma notes during the mastication, to indicate the time of the first swallowing and then to score the intensity of the two aroma notes after each swallowing event, during a total time of $3 \mathrm{~min}$. During mastication and at each swallowing time, the intensity of each aroma note was scored on the continuous scale (0-10). Each of the four cheeses was presented three times, in a random order, at $17^{\circ} \mathrm{C}$. From the aroma intensity perception at each swallowing event and the time of each swallowing event, time-intensity curves were reconstituted for each aroma note and the following parameters were extracted: Imax_S for maximum intensity, Tmax_S for time to reach maximum intensity, Ideg_S for intensity at the first swallowing and Tend_S for time to reach the end of perception (Fig. 1). The rate of perception (Vmax_S = Imax_S/Tmax_S) was then calculated as a fifth variable.

Insert Figure 1

\section{In vivo aroma release measurement}

The same protocol was applied for cheese consumption than that described for sensory analysis. The release of the two aroma compounds was followed simultaneously in the nasal cavity as previously described ${ }^{16}$ using Atmospheric Pressure Chemical lonisation-Mass Spectrometry (APCI-MS) with an ion trap Esquire-LC mass spectrometer (Bruker Daltonique, Wissembourg, France) according to their protonated molecular ion $\left(\mathrm{MH}^{+}\right)$, which is the main ion: ethyl propanoate $(\mathrm{m} / \mathrm{z}=103)$ and nonan-2-one $(\mathrm{m} / \mathrm{z}=143)$. Air was sampled from the nose at an average flow rate of $37 \mathrm{~mL}$. $\mathrm{min}^{-1}$ via a fused silica capillary tubing (i.d. $=0.53 \mathrm{~mm}$ ) heated at $150{ }^{\circ} \mathrm{C}$ and to which a $5 \mathrm{kV}$ positive ion corona pin discharge was applied. Each subject was asked to position the plastic tube in one nostril (the same for all the experiments) and to breathe normally. This period (breath-blank phase) was used to record the potential residual signal of the previous sample until return to the baseline and to control the regularity of breathing.

The curves were smoothed using a wavelet decomposition method to eliminate signal fluctuations due to the subjects' breathing patterns. Two release phases were identified, the chewing phase (1) extended from placing the cheese in the mouth to the first swallowing, and the post-swallowing phase (2) extended from the first swallowing to the time at which the signal returned to its baseline level. For both release phases and for each aroma compound, four main parameters were extracted from each individual release curve: the area under the curve (A1_P and A2_P (a.u.: arbitrary unit)) representing the quantity of aroma released, the maximum intensity (IMax1_P and IMax2_P (a.u.)), the time to reach maximum intensity (tMax1_P and tMax2_P $(\min ))$ and the release rate $\left(\operatorname{Vmax} P=I M a x 1 \_P /\right.$ tMax1_P (a.u./min)). These data, also not quantitative, allow a direct comparison of the different release curves.

\section{Chewing activity}


Chewing activity was monitored during cheese consumption, simultaneously to aroma release. The muscle activity of the superficial masseter and temporis muscles (left and right) during chewing was recorded by electromyography (EMG) using gold surface electrodes (Grass technologies, West Warwick, RI, U.S.A), at $382 \mathrm{~Hz}$, then the signal was amplified and digitalized $^{53}$. The following parameters were extracted from EMG data: number of chewing cycles (Nber_Cycle), chewing duration (Chew_time expressed in s), total muscle work (W_tot expressed in mV.s-1) and mean amplitude of contraction (Ampl expressed in $\mathrm{mV}$ ) which corresponds to a mean calculated from the amplitude values of each chewing cycle registered in a whole chewing sequence ${ }^{20}$.

\section{Bolus saliva content}

219 The percentage of dry matter and water content were determined using an infrared dryer for all cheeses and boluses obtained just before swallowing. The percentage of moistening (Moist \%) into the bolus was calculated from the bolus water content (Bwc \%), the bolus dry matter (Bdm \%), the cheese dry matter (Cdm \%) and the cheese water content (Cwc $\%)$ as follows:

$\operatorname{Moist}(\%)=\left(\frac{B w c}{B d m} \times C d m\right)-C w c$

Three replicates per cheese and per subject were performed.

225

226

227

228

Bolus rheology

The subjects were instructed to chew the cheese samples until swallowing and to spit out the bolus into a truncated syringe. Bolus rheological properties were measured using a compression test on an aliquot of $3 \mathrm{~mL}$ of bolus ${ }^{20}$. The test was performed using a mobile circle upper plate and a fixed circle lower plate as compression device, with a compression rate of $1 \mathrm{~mm} \cdot \mathrm{s}^{-1}$. The bolus was subjected to a force $\mathrm{F}$ ranging between $0.01 \mathrm{~N}$ and $50 \mathrm{~N}$. From the compression curve, particularly two phases were highlighted. A "flow phase" during which the suspension begins to flow and the particles move significantly in relation to one another at a height denoted as hflow $(\mathrm{mm})$. Yield stress and viscous effects were described respectively by the parameters sflow $(\mathrm{Pa})$ and Kflow (Pa.s). A "particle phase" during which the mechanical response is governed by the particle size which is represented by a height denoted hpart $(\mathrm{mm})$ and the yield stress component denoted spart $(\mathrm{Pa})$. At the end of the compression, hend $(\mathrm{mm})$ denotes the final height and Send $\left(\mathrm{mm}^{2}\right)$ the area generated under the maximal force. All measurements were done in triplicate.

\section{Mouth coating}


239

240

241

242

243

244

245

246

247

248

249

250

251

252

253

254

255

256

257

258

259

260

261

262

263

264

265

266

267

268

The amount of food that sticks to the oral surface after food ingestion (QRB) was quantified by the "mouth rinse" method ${ }^{54}$. Curcumin (Naturex, France) was added during cheese production (30 mg.kg ${ }^{-1}$. Each subject was asked to place a piece of cheese $\left(6 \mathrm{~g}\right.$, at $\left.17^{\circ} \mathrm{C}\right)$ in the mouth and to chew normally until swallowing. The subjects swallowed without cleaning movement and then rinsed their mouth (with cleaning movements) with $4 \mathrm{~mL}$ of warm water at $50^{\circ} \mathrm{C}$ for $30 \mathrm{~s}$, and spat it into a vial. This rinsing procedure was applied two times consecutively and the spittle was cumulated in the same vials. The fluorescence intensity of curcumin was quantified using a Perkin Elmer 1420 Multilabel Counter Victor $3 \mathrm{~V}$ at an excitation wavelength of $450 \mathrm{~nm}$ and an emission wavelength of $510 \mathrm{~nm}$. All measurements were done in triplicate.

\section{Statistical analyses}

Analyses of variance (ANOVA) and Principal Component Analysis (PCA) were performed using XLSTAT ${ }^{\circ}$ Software (Excel 97, version 8.0, Paris, France). When a significant effect $(p<0.05)$ was revealed by applying ANOVA, the Student-Newman-Keuls test was used to compare the differences in least-squares (LS) means.

Statistical treatments for Partial lest Square (PLS) analysis were performed using the free software R 3.3.0 (http://cran. rproject.org/ ), as already described for the treatment of in vivo release data obtained with the same cheeses and 48 subjects ${ }^{22}$. The main $\mathrm{R}$ package used for multivariate data analyses was «pls $2.5-0{ }^{55}$. In a preliminary stage, the statistical treatment consisted in a pre-processing step ${ }^{56}$. More precisely, all the variables are mean centered; then the blocks of variables are set to the same total variance. Finally, in order to explore the systematic variation patterns in the $\mathrm{X}$ blocks which are likely to predict the systematic variation patterns in Y, Multiblock -PLSR (MB-PLSR) is applied.

The different variables used in the MB-PLS approach are presented in Table 1. They have been divided in six blocks. The $Y$ block corresponds to the variables to be explained that is, the sensory variables. The five other blocks correspond to the explanatory variables (X1-X5). X1 is related to aroma release variables before (1) and after swallowing (2) as previously described. The variables in the subsequent blocks were selected as highly impacting the in vivo aroma release $\mathrm{e}^{22} \mathrm{X} 2$ is related to bolus rheological variables and bolus moistening. X3 is related to mouth coating and oral volume. X4 is related to masticatory variables extracted from the EMG signals. X5 is related to the properties of stimulated saliva. Insert Table1

\section{Results}

\section{Subjects' physiology}

The 14 subjects were selected from the 48 subjects participating to the in vivo release measurements ${ }^{16}$. Their physiological characteristics (Table 2) cover the range of variability observed for the 48 subjects as presented in the PCA representation 
269

270

271

272

273

274

275

276

277

278

279

280

281

282

283

284

285

286

287

288

289

290

291

292

293

294

295

296

297

298

299

(Fig.2). The principal plan represents $47 \%$ of the information. Axis $1(26.76 \%)$ is explained by the salivary flow (Flux_S) and the amount of sodium (Na_S) on its positive part, which are higher for subjects S027 and S094. Axis 2 (20.14\%) is explained by the amount of amylase (Amylase_S), the amount of salivary proteins (Prot_S) and the oral volume (Oral_vol) on its positive part, in relation with subjects S001, S052 and S086. At the opposite, S004 has a very low amount of amylase.

Insert Table 2.

Insert Figure 2

Time intensity perception

From the time intensity curves obtained for the four cheeses, 14 subjects and two odour notes, four variables were extracted namely, maximum intensity (Imax_S), time to reach the maximum intensity (Tmax_S), intensity at the first swallowing (Ideg_S) and time at the end of perception (Tend_S). The fifth variable, rate of perception (Vmax_S = Imax_S/Tmax_S) was calculated. Due to the high inter-individual differences between subjects only two variables show significant differences between the cheeses. Tmax_S is significantly higher $(p=0.002)$ for the blue cheese aroma (NO) detected in low fat cheeses (IfS and IfF) and Vmax_S is significantly higher $(p=0.07)$ for the fruity aroma (EP) detected in high fat soft cheese (hfS). Means and standard deviations for the different cheeses are reported in supplementary Table S1.

The high inter-individual variability was also observed on the in vivo release variables for the 48 subjects, which was explained by differences in physiological parameters. Results of in vivo aroma release have already been published $^{16}$, However the data obtained for the 14 subjects selected for the sensory analysis are available in supplementary Table S2. In order to better highlight the subject effect, a multiblock PLS analysis was performed on these 14 subjects to explain sensory perception for each cheese and each aroma compound by the in vivo release variables together with the physiological variables (Table 1).

\section{Relating sensory perception to in vivo aroma release and physiological parameters using MB-PLS}

MB-PLS is an extension of the PLS method, a class of regression models attempting to find relationships between explanatory and response variables. In MB-PLS, the predictor variables are separated into subsets or blocks that are standardized in order to balance for the size effect due to the measurement scale. It is a statistical approach particularly relevant when different data sets reflecting different dimensions (physiology, physic, chemistry ..) and with a different number of variables in each set are considered.

MB-PLS analyses were conducted on the different data sets to assess the extent to which the $\mathrm{X}$ blocks of variables explain sensory perception during cheese matrix consumption (Fig. 3 and Fig. 5). The four cheeses and the two 
300

301

302

303

304

305

306

307

308

309

310

311

312

313

314

315

316

317

318

319

320

321

322

323

324

325

326

327

328

329

330

aroma compounds nonan-2-one (NO) and ethyl propanoate (EP) were considered separately for the statistical treatment.

Two different results are presented from MB-PLS analysis in the following sections, the importance of the block and the projection of the variables in the correlation circle. At first, the importance of the blocks is calculated from the sum of the beta-weight of the different variables constitutive of the block related to the corresponding component and is expressed in \%. It thus reflects the contribution of the block of variables to the determination of the component. Higher is the percentage, higher is the contribution of the block for explaining sensory data. Complementary to the importance of the blocks, the projections correspond to the depiction in a correlation circle of the variables belonging to the different blocks. They thus represent the importance of the variables to the components. Higher a variable is correlated to the components, higher it contributes to the model and thus to explain perception.

The choice of the number of MB-PLS components to be retained for the importance of the block and the projections was based on the total variance of block $Y$ recovered by these components. For more details regarding this aspect, we refer to a previous paper ${ }^{22}$. We restrict ourselves to the first two components because they explain between $45.3 \%$ and $56 \%$ of the total variance of $Y$ for the high fat cheeses and the two aroma compounds and between 36.5 and $50.4 \%$ for the low fat cheeses and the two aroma compounds.

In order to avoid cumbersome graphical displays on the projections, only the variables with a correlation coefficient with one of the two first components above 0.5 are depicted. The font size for each variable on the projection (Fig. 4 and Fig. 6) reflects the importance of the correlation coefficient with the first two components; with large font size indicating large correlations.

The results from the MB-PLS are presented and discussed successively for high fat cheeses and for low fat cheeses.

\section{Relative Importance of the blocks in the projection for high fat cheeses}

The importance of the blocks of variables for the two first MB-PLS components is shown in figure 3 for the two high fat cheeses and the two aroma compounds. The release block is important for the high fat firm cheese (hfF) and both molecules and this on the two components $(31.7 \%$ for NO on component 1 and $37 \%$ for EP on component 2) and less important for high fat soft cheeses (with a maximum of contribution of $18.5 \%$ ). The bolus rheology block is mainly reflected by the second component for EP (25.9\% for hfF-EP and 31.5\% for hfS-EP) and less reflected for NO. The importance of coating and oral volume is higher for EP than for NO, on the first component. The masticatory variables take an important part in the explanation for both cheeses and both aroma compounds. Notice also the high contribution of stimulated saliva, mainly for hfS-NO (48.9\% on component 1 and 
331

332

333

334

335

336

337

338

339

340

341

342

343

344

345

346

347

348

349

350

351

352

353

354

355

356

357

358

359

360

361

362

$24.8 \%$ on component 2 ) for which the masticatory variables are less important ( $12.5 \%$ on component 1 and $21.3 \%$

on component 2 ).

Insert Figure 3

Insert Figure 4

\section{Projection of the main variables for high fat cheeses}

Figure 4 shows the projection of the variables from each block for the two high fat cheeses (hfF and hfS) and the two aroma compounds (EP and NO). The sensory variables from the Y block (variables to be explained) are negatively correlated with component 1 and for the high fat soft cheese, the rate of perception is negatively correlated with component 2 . The other variables (explanatory variables) are projected differently according to both the cheese and the aroma compound. For the high fat firm cheese and ethyl propanoate (hfF-EP), the masticatory parameters are correlated with component 1, with the chewing time (Chew_time) and number of chewing cycles (Nber_Cycle) on the positive part and the amplitude (Ampl) on the negative part, the release parameters are correlated with component 2, with a higher correlation coefficient for Vmax_P and Imax1_P, the amount of product remaining in the mouth (QRB) is projected at the opposite of the maximum intensity perceived (Imax_S). Among the salivary parameters, the amount of proteins (Prot_S) is positively correlated with component 1, opposite to the amount of sodium (Na_S) and of amylase (Amylase_S). The amount of lipolysis (Lipolysis_S) is projected close to the QRB. For the high fat soft cheese and ethyl propanoate (hfF-EP), the most correlated explanatory variables are the bolus rheology properties, with Send and Moist negatively correlated with component 1 together with the sensory variables, opposite to hend and hpart. The masticatory parameters are also correlated with component 1 , with Chew_time and Nbe_Cycle on the positive part and Ampl on the negative part. Among the release parameters, only Imax1_P and A1_P are positively correlated with component 1 and Vmax_P with a lower correlation. QRB is also projected opposite to Imax_S. Concerning the high fat firm cheese and nonan-2-one (hfF-NO), the masticatory parameters (Chew_time and Nbe_Cycle) are also positively correlated with component 1 and negatively with component 2, the release parameters before swallowing (Imax1_P and A1_P) are positivele correlated with component 1 whereas the release parameters after swallowing (Imax2_P, A2_P) are negatively correlated with component 2 . Concerning the high fat soft cheese and nonan-2-one (hfS-NO), the salivary parameters are well represented on the projection, mainly Flux_S and $\mathrm{Na \_ S}$, positively correlated with component 1 and component 2 and opposite to the maximum intensity perceived. The release parameters have only low correlations with these two components as represented by their small font size, but the time to reach maximum intensities both before and after swallowing (tmax1_P and tmax2_P) are positively correlated with component 2, opposite to the rate of perception. The masticatory parameters and QRB are negatively correlated with component 1.

\section{Relative Importance of the blocks in the projection for low fat cheeses}


363

364

365

366

367

368

369

370

371

372

373

374

375

376

377

378

379

380

381

382

383

384

385

386

387

388

389

390

391

392

393

394

The importance of the blocks of variables for the two first MB-PLS components is shown in figure 5 for the two low fat cheeses and the two aroma compounds. The relative importance of the release block is always below $28 \%$, it is higher for nonan-2-one and the firm cheese (IfF-NO, $27.5 \%$ on component 1 and $14.9 \%$ on component 2 ) and for ethyl propanoate and the soft cheese (IfS-EP, $20.7 \%$ on component 1 and $19.8 \%$ on component 2). The bolus rheology block is reflected on the two components with a contribution of $19.2 \%$ on component 1 and $6.8 \%$ on component 2 for IfF-NO, $17.4 \%$ on component 1 and $29 \%$ on component 2 for IfS-NO and intermediates for EP. Coating and oral volume are highly important for IfF-NO (25.2\% on component 1 and $29.8 \%$ on component 2 ) and IfS-EP (48.7\% on component 2). The masticatory properties have a high impact on fruity aroma (EP) in the low fat firm cheese $(46.5 \%$ on component 1 and $47 \%$ on component 2 ), and in the low fat soft cheese ( $41.3 \%$ on component 1$)$ but they seem to impact less blue cheese aroma (NO). For nonan-2-one the salivary parameters are more relevant to explain sensory perception with $22.2 \%$ of contribution on component 1 and $28.5 \%$ on component 2 for low fat firm cheese and $14.8 \%$ on component 1 and $46.5 \%$ on component 2 for low fat soft cheese.

Insert Figure 5

Insert Figure 6

Projection of the main variables for low fat cheeses

Figure 6 shows the projection of the variables from each block for the two low fat cheeses and the two aroma compounds on the two first MB-PLS components.

For the low fat firm cheeses (IfF), the sensory variables related to aroma persistence (Tmax_S and Tend_S) are negatively correlated with component 1 , whereas the rate of perception (Vmax_S) and the maximum intensity of perception (Imax_S) are negatively correlated with component 2 for ethyl propanoate and positively for nonan-2one. For the low fat soft cheeses, the rate of perception (Vmax_S) is positively correlated with component 1, the maximum intensity (Imax_S) negatively with component 2, whereas the times (Tmax_S and Tend_S) are negative correlated with component 1 for ethyl propanoate and negatively correlated with component 2 for nonan-2-one. Concerning the explanatory variables, the masticatory parameters (Chew_time and Nber_Cycle) are negatively correlated with component 1 for IfS cheese and the 2 aroma compounds and for IfF cheese and ethyl propanoate but negatively correlated with component 2 for IfF cheese and nonan-2-one, whereas the amplitude is negatively correlated with component 2 only for IfF cheese and ethyl propanoate. Concerning the bolus rheology parameters Hend, hpart and Kflow are always positive correlated with component 1 and component 2 whereas Moist and Send are negatively correlated with component 1 and component 2 . Concerning the release parameters, tmax2_P is always negative correlated with component 1 , the other parameters have lower correlations on this plan, except Vmax_P on the positive part of component 1 for IfF cheese and ethyl propanoate, Imax1_P on the positive part of component 1 and negative part of component 2 for IfF cheese and nonan-2-one, A2_P and A_P for both cheese 
395

396

397

398

399

400

401

402

403

404

405

406

407

408

409

410

411

412

413

414

415

416

417

418

419

420

421

422

423

424

425

426

and nonan-2-one. The salivary parameters have only small correlations on this plane for the low fat soft cheese but for the low fat firm cheese, the salivary flow (Flux_S) and the amount of sodium (Na_S) are negatively correlated with component 2.

\section{Discussion}

Considering the results of MB-PLS on high fat cheeses (Fig. 4), different trends are observed for firm and soft cheeses. For the firm cheeses, the perception of fruity aroma is more related to the release of ethyl propanoate (EP) before swallowing whereas the perception of blue cheese aroma is more related to the release of nonan-2-one (NO) after swallowing. Ethyl propanoate which is less hydrophobic is released faster from the fat cheese matrix ${ }^{16}$, and thus perceived at the beginning of the oral processing for the firm cheese whereas nonan-2-one which is hydrophobic is released later and mainly after swallowing $^{19}$, which explains the longer time to reach maximum intensity and time to reach the end of perception. For the soft cheeses the same correlations are found for nonan-2-one whereas no such correlation is found between sensory parameters and release parameters for ethyl propanoate. Regarding the masticatory variables, it appears that the mean amplitude of contraction (Ampl) is well correlated with the rate of fruity perception (EP) on component 1 for firm cheese and component 2 for soft cheeses. This variable was already highlighted in our previous paper ${ }^{22}$ as responsible for a higher rate of EP release. Thus, we confirm that subjects with high amplitude per burst will release more rapidly the hydrophilic compound (EP) and we demonstate that this higher release rate induce a more rapid perception. The other masticatory variables better explain the blue cheese perception (NO) and more specifically aroma persistence. Subjects with a longer chewing time (Chew_time) and larger number of bursts (Nber_Cycle) have a longer duration of blue cheese aroma (Tmax_S and Tend_S) for both cheeses. This could also be explained by a longer time to reach the maximum NO release intensity after swallowing (tMax2_P). The bolus rheology properties impact fruity perception (EP) more, with a positive relationship between bolus moistening (Moist) and time to reach the end of perception (Tend-S), which could be explained by an important bolus spreadability (Send). Bolus moistening (Moist) impacts EP release intensity (Imax1_P), a high bolus moistening decreases the amount of release before swallowing. This could be explained by dilution with saliva which decreases the rate of release of hydrophilic aroma compounds as already proposed using in vitro ${ }^{57}$ and in silico models ${ }^{58}$ and thus will delay the perception by increasing the persistence. The amount of product remaining in the mouth (QRB) explains the perception of both aroma notes. QRB corresponds to the fat coating at the surface of the tongue and oral mucosa after swallowing ${ }^{54}$. For blue cheese perception (NO), it could be thus due to the retention of NO, hydrophobic aroma compounds, in the fat, which delays its release and then enhances its perception. Conversely, the fruity perception (EP) is projected opposite to fat coating in the mouth, i.e. higher is the coating lower is the perception. Many salivary parameters impact aroma perception. Sodium concentration in saliva ( $\left.\mathrm{Na}_{-} \mathrm{S}\right)$ positively influences fruity perception (EP) and negatively blue cheese perception (NO), whereas it was not found to have a strong impact on in vivo aroma release $\mathrm{e}^{22}$. 
427

428

429

430

431

432

433

434

435

436

437

438

439

440

441

442

443

444

445

446

447

448

449

450

451

452

453

454

455

456

457

458

Salivary lipolysis (Lipolysis_S) was depicted in the same direction of QRB in three projections (hfF-EP, hfF-NO and hfS-NO) witnessing a different impact on sensory perception depending on the fruity (EP) or blue cheese (NO) note. Salivary flow (Flux_S), protein content (Prot_S), amylase activity (Amylase_S) also impact sensory perception but differently according to the cheese and the aroma notes.

As for high fat cheeses, different trends are observed between firm and soft low fat cheeses (Fig. 6). For the low fat firm cheese (IfF) aroma persistence (Tmax_S and Tend_S) can be explained by the time to reach maximum aroma release after swallowing (tMax2_P), the amount of product remaining in the oral cavity (QRB) and the oral volume (Oral_Vol) for the two aroma compounds whereas the chewing time (Chew_time) and the number of chewing cycles (Nber_Cycle) mainly explain fruity perception (EP). These correlations are logical because a higher amount of product remaining in the mouth increases the amount of aroma released after swallowing ${ }^{22}$ which should increase aroma persistence. Moreover a longer chewing time increases the total amount of aroma released ${ }^{17}$ and thus aroma perception. The mean amplitude of contraction (Ampl) is depicted very similarly to the rate of perception (Vmax_S) of the fruity note as it was the case for high fat cheeses. Similar to high fat cheeses, stimulated saliva composition and in particular the sodium content ( $\mathrm{Na} \_$S) impact aroma perception. High sodium content is related to a high fruity aroma (EP) and low blue cheese aroma (NO) intensity.

For the low fat soft cheeses (IfS), similar trends are observed for the fruity aroma (EP) but not for blue cheese aroma (NO). The blue cheese aroma perception (NO) cannot be logically explained by NO release but is related to saliva composition and more precisely to lipolysis (Lypolysis_S). Bolus moistening and bolus rheology highly contribute to the perception of the two aroma notes. A higher aroma perception is related to a higher moistening (Moist) and higher bolus spreadability which is explained by the area at the end of compression (Send). These results are also in line with the higher salivary flow (Flux_S).

Thanks to MB-PLS statistical approach, some general trends can be highlighted concerning the explanation of sensory perception by release and physiological properties. When consuming solid foods containing fat such as cheeses, masticatory behaviour highly impacts the dynamic of aroma release and thus aroma perception. A large mean amplitude of contraction increases rate of release and rate of perception. A longer chewing time increases the time to reach maximum intensity after swallowing and the time to reach maximum perceived intensity. Concerning the variables from the other blocks, the relationships are not always so simple to interpret, which may be due to interactions between these variables. A high salivary flow leads to a high bolus moistening, a large bolus area at the end of compression indicating a high bolus spreadability, which results in a lower rate of aroma release ${ }^{22}$ but the direct consequence on aroma perception is not clearly evidenced. 
459

460

461

462

463

464

465

466

467

468

469

470

471

472

473

474

475

476

477

478

479

480

481

482

483

484

485

486

487

However some variables were found to be related to sensory perception and not to aroma release. This is the case for specific variables of saliva composition. The most striking finding is that lipolysis which is depicted in the same direction to fat coating for NO and EP, is also depicted in the NO projection in the same direction to sensory variables, while the opposite is observed for EP. This was particularly emphasized for high-fat cheeses. Salivary lipolysis has been described as a marker of fat sensitivity and liking in human ${ }^{41}$. For example, a positive correlation was found between the level of lipolysis and perceived fat intensity while the opposite was observed for liking in subjects $^{51}$ with a normal weight. On obese subjects, in vivo inhibition of lingual lipase led to a significant enhancement of their sensory threshold for triolein ${ }^{59}$. Moreover, compared to normal-weight subjects, obese individuals exhibited a significant low level of salivary lipolysis thus reflecting the higher liking for fat as reported in this population ${ }^{48,60}$. Concerning coating, fatty perception of oil in water emulsions has been previously related to the level of fat retention at the surface of the tongue after consumption ${ }^{61,62}$. Altogether, these findings tend to substantiate a positive correlation between the level of salivary lipolysis, fat coating and fat perception. These findings support our hypothesis of cross-modal interactions between aroma perception and fattiness that differs depending on the aroma. For NO (blue cheese aroma), the similar depiction of lipolysis, fat coating and sensory variables should indicate a congruency between aroma perception and fat perception. Contrariwise, for EP (fruity aroma), the depiction between lipolysis, fat coating and sensory variables should indicate a negative interaction because of the non-congruency between this aroma and fat perception.

A similar hypothesis can be proposed for the effect of sodium content in stimulated saliva on aroma perception. This property is depicted in the same direction as sensory variables for EP whereas it is in the opposite direction for NO. The amount of sodium in saliva has already been described as an important factor which contributes in the sensitivity for salt, i.e. the higher the concentration, the higher the detection threshold ${ }^{63-66}$. As for lipolysis, it is likely that subjects exhibiting a high sodium concentration had a lower saltiness perception. Following our hypothesis regarding the existence of salty-aroma interactions and considering that blue cheese aroma, unlike fruity aroma, could be congruent to saltiness, subjects with a low salivary sodium content may perceive the cheeses as being saltier. Since the subjects were instructed to rate the aroma intensity only and not the salty taste in the cheese products during the sessions, they should have reported their salty perception on the blue cheese aroma which is congruent with salty perception, due to a dumping effect ${ }^{34}$. Contrariwise, the perception of a fruity note may be increased for the subjects with high sodium content who perceived the cheeses as less salty, because this aroma is not congruent with salty.

\section{Conclusions}


489

490

491

492

493

494

495

496

497

498

499

500

501

502

503

504

505

506

507

508

509

510

511

512

As a conclusion, this study allowed us to highlight the respective impacts of in vivo aroma release and physiological properties on sensory perception. The originality of the approach is to consider all the variables together and evaluate their relative contribution. Our study confirms the important role of masticatory variables for firm cheeses and that of salivary properties for soft cheeses. The perception of the fruity aroma of the more hydrophilic compound (ethyl propanoate) is related to its dynamic release parameters before swallowing whereas the blue cheese aroma of the more hydrophobic compound (nonan-2-one) is related to its dynamic release parameters after swallowing and is highly impacted by mouth coating. Moreover, it was evidenced that dynamic in vivo aroma release does not always explain sensory perception. MB-PLS approach made it possible to evidence the combined effects of saliva composition and cross-modal interactions to understand why in some cases dynamic aroma perception could not be explained by dynamic in vivo aroma release data. Our study confirms the key role of salivary sodium content and lipolysis activity in sensory perception. The main finding is that subjects with a high sodium content in saliva perceive aromas which are not congruent with saltiness as more intense and saltcongruent aromas as less intense and that subjects with a high lipolysis activity perceive aromas which are not congruent to fat as less intense and fat-congruent aromas as more intense. These findings could help to better understand the inter-individual differences in aroma perception and could be considered for the reformulation of foods targeted for specific populations taking into account nutritional recommendations.

\section{Acknowledgements}

The acknowledgements come at the end of an article after the conclusions and before the notes and references.

This work received financial support from the French National Research Agency (ANR-07-PNRA-014), the Regional Council for Burgundy and FEDER (European Union). The authors thank Etienne Sémon from ChemoSens Platform (CSGA) for APCl experiments, Vincent Gigot from CSGA for APCI curve smoothing, Claude Yven for electromyography, Chantal Septier for subjecst's physiology and sensory analysis, Elsa Ropiteau for sensory analysis, Laboratoire de Rhéologie (Université Joseph Fourier Grenoble, France) for bolus rheology, Fromageries Bel SA, Soredab (groupe Soparind Bongrain) and the panellists. 


\section{References}

1. A. Buettner, S. Otto, A. Beer, M. Mestres, P. Schieberle and T. Hummel, Food Chemistry, $2008,108,1234-1246$.

2. M. Kopjar, I. Andriot, A. Saint-Eve, I. Souchon and E. Guichard, Journal of the Science of Food and Agriculture, 2010, 90, 1285-1292.

3. L. Boisard, C. Tournier, E. Semon, E. Noirot, E. Guichard and C. Salles, Flavour and Fragrance Journal, 2014, 29, 95-106.

4. S. Lubbers, P. Landy and A. Voilley, Food Technology, 1998, 52, 68-214.

5. A. Tromelin, I. Andriot and E. Guichard, in Flavour in food, eds. A. Voilley and P. Etiévant, Woodhead Publishing Limited, Cambridge, CB1 6AH, UK, CRC Press edn., 2006, vol. Part 2 Flavour retention and release from the food matrix, pp. 172-207.

6. A. Meynier, V. Rampon, M. M. Dalgalarrondo and C. Genot, International Dairy Journal, 2004, 14, 681-690.

7. I. Andriot, M. Harrison, N. Fournier and E. Guichard, Journal of Agricultural and Food Chemistry, 2000, 48, 4246-4251.

8. J. Delarue and P. Giampaoli, in Flavour in food, eds. A. Voilley and P. Etievant, Woodhead Publishing Limited and CRC Press LLC, Cambridge, CB1 6AH (GBR), CRC Press edn., 2006, pp. 208-228.

9. S. Lubbers and E. Guichard, Food Chemistry, 2003, 81, 269-273.

10. C. Heinemann, M. Zinsli, A. Renggli, F. Escher and B. Conde-Petit, LWT - Food Science and Technology, 2005, 38, 885-894.

11. C. Salles, M. C. Chagnon, G. Feron, E. Guichard, H. Laboure, M. Morzel, E. Semon, A. Tarrega and C. Yven, Critical Reviews in Food Science and Nutrition, 2011, 51, 67-90.

12. A. J. Taylor, R. S. T. Linforth, B. A. Harvey and A. Blake, Food Chemistry, 2000, 71, 327-338.

13. W. Lindinger, A. Hansel and A. Jordan, International Journal of Mass Spectrometry and lon Processes, 1998, 173, 191-241.

14. E. Aprea, F. Biasioli, F. Gasperi, T. D. Märk and S. van Ruth, Flavour and Fragrance Journal, 2006, 21, 53-58.

15. M. Mestres, N. Moran, A. Jordan and A. Buettner, J. Agric. Food Chem., 2005, 53, 403-409.

16. M. Repoux, H. Laboure, P. Courcoux, I. Andriot, E. Semon, C. Yven, G. Feron and E. Guichard, Flavour and Fragrance Journal, 2012, 27, 414-423.

17. A. Tarrega, C. Yven, E. Sémon and C. Salles, International Dairy Journal, 2008, 18, 849-857.

18. A. B. Boland, C. M. Delahunty and S. M. van Ruth, Food Chemistry, 2006, 96, 452-460.

19. L. Boisard, I. Andriot, C. Martin, C. Septier, V. Boissard, C. Salles and E. Guichard, Food Chemistry, 2014, 145, 437-444.

20. C. Yven, J. Patarin, A. Magnin, H. Labouré, M. Repoux, E. Guichard and G. Feron, Journal of Texture Studies, 2012, 43, 309-318.

21. S. Prakash, D. D. Y. Tan and J. S. Chen, Food Research International, 2013, 54, 1627-1635.

22. G. Feron, C. Ayed, E. M. Qannari, P. Courcoux, H. Labouré and E. Guichard, PLoS One, 2014, 9, 1-15.

23. C. Tournier, C. Sulmont-Rosse and E. Guichard, in Food, ed. G. S. Books, Global Science Books LtD., Royaume-Uni (GBR), 2007, vol. 1, pp. 246-257.

24. I. Gierczynski, E. Guichard and H. Laboure, Flavour and Fragrance Journal, 2011, 26, 141-152.

25. A. Saint-Eve, N. Martin, H. Guillemin, E. Sémon, E. Guichard and I. Souchon, Journal of Agricultural and Food Chemistry, 2006, 54, 7794-7803.

26. I. Gierczynski, H. Laboure and E. Guichard, Journal of Agricultural and Food Chemistry, 2008, 56, 1697-1703. 
27. J. H. F. Bult, R. A. de Wijk and T. Hummel, Neurosci. Lett., 2007, 411, 6-10.

28. S. Leclercq and G. Blancher, Chem. Senses, 2012, 37, 689-700.

29. G. Fiches, A. Saint Eve, S. Jourdren, I. Deleris, P. Bruneriea and I. Souchon, Flavour and Fragrance Journal, 2016, 31, 31-40.

30. B. Atanasova, T. Thomas-Danguin, D. Langlois, C. Chabanet, S. Nicklaus and P. Etievant, Chem. Senses, 2005, 30, A28.

31. M. Charles, A. Romano, S. Yener, M. Barnaba, L. Navarini, T. D. Mark, F. Biasoli and F. Gasperi, Food Research International, 2015, 69, 9-20.

32. H. N. J. Schifferstein and P. W. J. Verlegh, Acta Psychologica, 1996, 94, 87-105.

33. R. J. Stevenson, R. A. Boakes and J. Prescott, Learning and Motivation, 1998, 29, 113-132.

34. C. C. Clark and H. T. Lawless, Chem. Senses, 1994, 19, 583-594.

35. J. Niimi, A. I. Eddy, A. R. Overington, P. Silcock, P. J. Bremer and C. M. Delahunty, International Dairy Journal, 2014, 39, 222-228.

36. A. Tarrega, C. Yven, E. Semon and C. Salles, International Dairy Journal, 2011, 21, 358-364.

37. M. Doyennette, C. de Loubens, I. Deleris, I. Souchon and I. C. Trelea, Food Chemistry, 2011, 128, 380-390.

38. C. Méjean, M. Morzel, E. Neyraud, S. Issanchou, C. Martin, S. Bozonnet, C. Urbano, P. Schlich, S. Hercberg, S. Péneau and G. Feron, PLoS One, 2015, 10, e0137473.

39. L. Engelen, P. A. M. van den Keybus, R. A. de Wijk, E. C. I. Veerman, A. V. N. Amerongen, F. Bosman, J. F. Prinz and A. van der Bilt, Archives of Oral Biology, 2007, 52, 518-525.

40. A. L. S. Ferry, J. R. Mitchell, J. Hort, S. E. Hill, A. J. Taylor, S. Lagarrigue and B. Valles-Pamies, Journal of Agricultural and Food Chemistry, 2006, 54, 8869-8873.

41. G. Feron and J. Poette, Oilseeds and fats, Crops and Lipids, 2013, 20, 102-107.

42. J. Poette, J. Mekoué, E. Neyraud, O. Berdeaux, A. Renault, E. Guichard, C. Genot and G. Feron, Flavour and Fragrance Journal, 2014, 29, 39-49.

43. A. Buettner, Journal of agricultural and food chemistry, 2002, 50, 3283-3289.

44. A. Buettner, Journal of Agricultural and Food Chemistry, 2002, 50, 7105-7110.

45. S. Pagès-Hélary, I. Andriot, E. Guichard and F. Canon, Food Research International, 2014, 64, 424-431.

46. P. Piombino, A. Genovese, S. Esposito, L. Moio, P. P. Cutolo, A. Chambery, V. Severino, E. Moneta, D. P. Smith, S. M. Owens, J. A. Gilbert and D. Ercolini, PLoS One, 2014, 9, e85611.

47. R. Matsuo, Crit. Rev. Oral Biol. Med., 2000, 11, 216-229.

48. L. M. Bartoshuk, V. B. Duffy, J. E. Hayes, H. R. Moskowitz and D. J. Snyder, Phil. Trans. R. Soc. B, 2006, 361, 1137-1148.

49. A. Mishellany-Dutour, A. Woda, H. Laboure, P. Bourdiol, P. Lachaze, E. Guichard and G. Feron, PLoS One, 2012, 7, e41276.

50. S. R. Drago, M. Panouille, A. Saint-Eve, E. Neyraud, G. Feron and I. Souchon, Food Hydrocolloids, 2011, 25, 659-667.

51. E. Neyraud, O. Palicki, C. Schwartz, S. Nicklaus and G. Feron, Archives of Oral Biology, 2012, 57, 556-566.

52. M. Emorine, C. Septier, T. Thomas-Danguin and C. Salles, Food Research International, 2013, 51, 641-647.

53. L. Mioche, P. Bourdiol and S. Monier, Archives of Oral Biology, 2003, 48, 193-200.

54. M. Repoux, C. Septier, O. Palicki, E. Guichard, G. Feron and H. Labouré, Archives of Oral Biology, 2012, 57, 81-86.

55. B. H. Mevik and R. Wehrens, J. Stat. Softw., 2007, 18, 1-24.

56. S. Hassani, H. Martens, E. L. Qannari, M. Hanafi and A. Kohler, Chemometrics and intelligent laboratory systems, 2012, 117, 42-53.

57. S. Odake, J. P. Roozen and J. J. Burger, Nahrung, 1998, 42, 385-391.

58. M. Doyennette, I. Déléris, G. Féron, E. Guichard, I. Souchon and I. C. Trelea, Journal of Theoretical Biology, 2014, 340, 209-221. 
59. M. Y. Pepino, L. Love-Gregory, S. Klein and N. A. Abumrad, Journal of Lipid Research, 2012, 53, 561-566.

60. C. Vors, J. Drai, L. Gabert, G. Pineau, M. Laville, H. Vidal, E. Guichard, M.-C. Michalski and G. Feron, International Journal of Obesity, 2015, 39, 1425-1428.

61. S. Camacho, K. Liu, A. Linden, M. Stieger and F. Velde, Journal of Texture Studies, 2015, 46, 399-410.

62. S. Camacho, V. van Riel, C. de Graaf, F. van de Velde and M. Stieger, Journal of Agricultural and Food Chemistry, 2014, 62, 5789-5795.

63. L. M. Bartoshuk, The American Journal of Clinical Nutrition, 1978, 31, 1068-1077.

64. R. J. Contreras and F. A. Catalanotto, Behavioral and neural biology, 1980, 29, 303-314.

65. J. Delwiche and M. O'Mahony, Physiology \& Behavior, 1996, 59, 605-611.

66. T. Morino and H. G. Langford, Physiology \& Behavior, 1978, 21, 45-48. 
Table 1: presentation of the different blocks of variables used in the -MB-PLS Analyses. Y: variables to be explained, X: explanatory variables. a.u.: arbitrary units

\begin{tabular}{|c|c|c|}
\hline Block & Abbreviation & Definition of the variable \\
\hline \multirow{5}{*}{$\begin{array}{l}\text { Y: sensory } \\
\text { parameters }\end{array}$} & Imax_S & Maximum intensity perceived (a.u.) \\
\hline & Tmax_S & Time to reach the maximum intensity (s) \\
\hline & Vmax_S & Rate of perception (a.u./s) \\
\hline & Ideg_S & Maximum intensity at swallowing (a.u.) \\
\hline & Tend_S & Time to reach the end of perception (s) \\
\hline \multirow{8}{*}{$\begin{array}{l}\text { X1: aroma } \\
\text { release } \\
\text { parameters }\end{array}$} & A1_P & Area under the curve before $1^{\text {st }}$ swallowing (a.u.) \\
\hline & $A 2 \_P$ & Area under the curve after $1^{\text {st }}$ swallowing (a.u.) \\
\hline & A_P & Total area under the curve $\left(\mathrm{A}=\mathrm{A} 1 \_\mathrm{P}+\mathrm{A} 2 \_\mathrm{P}\right)$ \\
\hline & IMax1_P & Maximum intensity before $1^{\text {st }}$ swallowing (a.u.) \\
\hline & tMax1_P & Time to reach maximum intensity before $1^{\text {st }}$ swallowing (s) \\
\hline & IMax2_P & Maximum intensity after $1^{\text {st }}$ swallowing (a.u.) \\
\hline & tMax2_P & Time to reach maximum intensity after $1^{\text {st }}$ swallowing (s) \\
\hline & Vmax_P & Rate of release (a.u./s) \\
\hline \multirow{8}{*}{$\begin{array}{c}\text { X2: } \\
\text { Bolus rheology }\end{array}$} & Moist & Moistening of the bolus just before the swallowing (\%) \\
\hline & sflow & Yield stress at flow phase of compression curve (Pa) \\
\hline & spart & Yield stress at particle phase of compression curve ( $\mathrm{Pa})$ \\
\hline & hpart & Bolus height at the beginning of the particle phase of compression curve $(\mathrm{mm})$ \\
\hline & Kflow & Consistency at the flow phase, which reflects bolus consistency (Pa.s) \\
\hline & hflow & Bolus height at the beginning of the flow phase of compression curve ( $\mathrm{mm})$ \\
\hline & hend & Bolus height at the end of compression ( $\mathrm{mm}$ ) \\
\hline & Send & Area at the end of compression $\left(\mathrm{mm}^{2}\right)$ \\
\hline X3: & QRB & Amount of product remaining in the oral cavity after swallowing (\%) \\
\hline Coating- oral vol & Oral_Vol & Volume of the oral cavity $\left(\mathrm{cm}^{3}\right)$ \\
\hline \multirow{4}{*}{$\begin{array}{l}\text { Masticatory } \\
\text { parameters }\end{array}$} & Nber_Cycle & Number of chewing cycle \\
\hline & Chew_time & Chewing duration (s) \\
\hline & Ampl & Mean amplitude of contraction (mV) \\
\hline & W_tot & Energy expended in chewing $(\mathrm{mV} / \mathrm{s})$ \\
\hline \multirow{6}{*}{$\begin{array}{c}\text { X5: } \\
\text { Properties of } \\
\text { stimulated saliva }\end{array}$} & Flux_S & Salivary flow stimulated saliva ( $\mathrm{ml} / \mathrm{min})$ \\
\hline & Prot_S & Amount of salivary proteins stimulated saliva $(\mathrm{mg} / \mathrm{ml})$ \\
\hline & Lipolysis_S & Amount of Lipolysis in stimulated saliva $(\mathrm{mU} / \mathrm{ml})$ \\
\hline & Amylase_S & Amount of Amylase in stimulated saliva $(\mathrm{U} / \mathrm{ml})$ \\
\hline & Proteolysis_S & Amount of Proteolysis in stimulated saliva $(\mathrm{U} / \mathrm{ml})$ \\
\hline & $\mathrm{Na}$ _S & Amount of sodium in stimulated saliva (mM) \\
\hline
\end{tabular}


Table 2: oral physiological characteristics of the 14 subjects included in the study, mean, standard deviation, minimum and maximum values.

\begin{tabular}{|c|c|c|c|c|c|}
\hline & & minimum & maximum & mean & $\begin{array}{l}\text { Standard } \\
\text { deviation }\end{array}$ \\
\hline Oral volume $\left(\mathrm{cm}^{3}\right)$ & Oral_Vol & 26.85 & 62.16 & 39.03 & 9.73 \\
\hline Stimulated salivary flow (ml/min) & Flux_S & 0.73 & 4.32 & 2.60 & 1.40 \\
\hline Protein $(\mathrm{mg} / \mathrm{ml})$ & Prot_S & 0.57 & 1.31 & 1.04 & 0.31 \\
\hline Lipolysis (mU/ml) & Lipolysis_S & $<0.01$ & 1.32 & 0.90 & 0.74 \\
\hline Amylase (U/ml) & Amylase_S & 1.27 & 30.6 & 20.86 & 11.00 \\
\hline Proteolysis (U/ml) & Proteolysis_S & 0.04 & 0.51 & 0.13 & 0.12 \\
\hline sodium content (mM) & $\mathrm{Na} \_\mathrm{S}$ & 2.09 & 37.82 & 15.82 & 11.03 \\
\hline
\end{tabular}


Figure captions:

Figure 1. Time intensity curves obtained for one subject for blue cheese aroma (NO: nonan-2-one) for the four cheeses (hfS: high fat soft, hfF: high fat firm, IfS: low fat soft, IfF: low fat firm) showing the extracted parameters (Imax_S: maximum intensity, Tmax_S: time to reach maximum intensity, Ideg_S: intensity at swallowing and Tend_S: time to reach the end of perception.

Figure 2. Bibplot representation from the PCA performed on the 14 subjects and their physiological parameters.

Figure 3. Bar charts representing the relative importance (\%) of the different blocks of variables (X1-X5) for the different components obtained by means of MB-PLS analysis performed on fruity aroma (EP) and blue cheese aroma (NO) sensory data set and for the high fat (hfF \& hfS) cheese products. Blue chart: X1-Aroma release, Green chart: X2-rheology, Orange chart: X3-coating and oral volume, Red chart: X4-EM data, Violet chart: X5-stimulated saliva composition.

Figure 4. MB-PLS results on $\operatorname{dim} 1 / \operatorname{dim} 2$ for high fat (hf) cheeses: relationships between the X-blocks of explanatory variables (Blue arrows: X1-aroma release, Green arrows: X2-rheology, Orange arrows: X3-coating and oral volume, Red arrows: X4EMG data, Violet arrows: X5-stimulated saliva composition) and the $Y$ block of variables to be explained (Black arrows: sensory data for fruity aroma (EP) and blue cheese aroma (NO). Top: firm high fat cheeses (hfF), bottom: soft high fat cheeses (hfS). The font size for each variable reflects the importance of the correlation coefficient with the two components.

Figure 5. Bar charts representing the relative importance (\%) of the different blocks of variables (X1-X5) for the different components obtained by means of MB-PLS analysis performed on fruity aroma (EP) and blue cheese aroma (NO) sensory data set and for the low fat (IfF \& IfS) cheese products. Blue chart: X1-Aroma release, Green chart: X2-rheology, Orange chart: X3-coating and oral volume, Red chart: X4-EM data, Violet chart: X5-stimulated saliva composition.

Figure 6. MB-PLS results on $\operatorname{dim} 1 / \operatorname{dim} 2$ for low fat (If) cheeses: relationships between the X-blocks of explanatory variables (Blue arrows: X1-aroma release, Green arrows: X2-rheology, Orange arrows: X3-coating and oral volume, Red arrows: X4EMG data, Violet arrows: X5-stimulated saliva composition) and the $Y$ block of variables to be explained (Black arrows: sensory data for fruity aroma (EP) and blue cheese aroma (NO). Top: firm low fat cheeses (IfF), bottom: soft low fat cheeses (IfS). The font size for each variable reflects the importance of the correlation coefficient with the two components. 


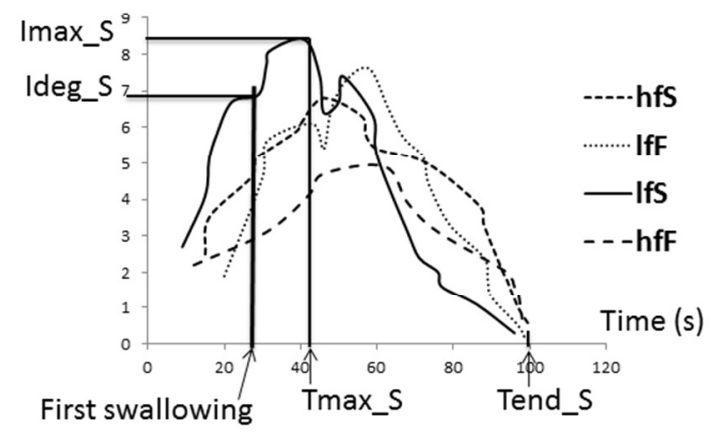

Figure 1. Time intensity curves obtained for one subject for blue cheese aroma (NO: nonan-2-one) for the four cheeses (hfS: high fat soft, hfF: high fat firm, IfS: low fat soft, IfF: low fat firm) showing the extracted parameters (Imax_S: maximum intensity, Tmax_S: time to reach maximum intensity, Ideg_S: intensity at swallowing and Tend_S: time to reach the end of perception.

254x190mm (96 x 96 DPI) 


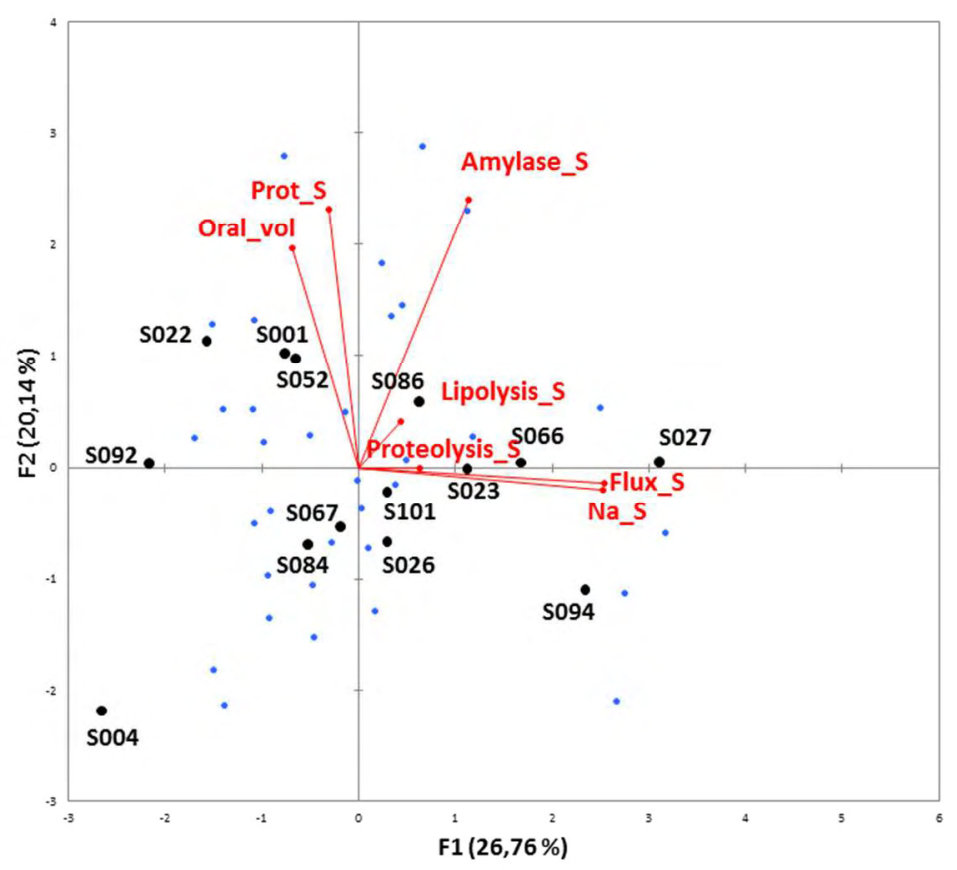

Figure 2. Bibplot representation from the PCA performed on the 14 subjects and their physiological parameters.

$254 \times 190 \mathrm{~mm}(96 \times 96 \mathrm{DPI})$ 


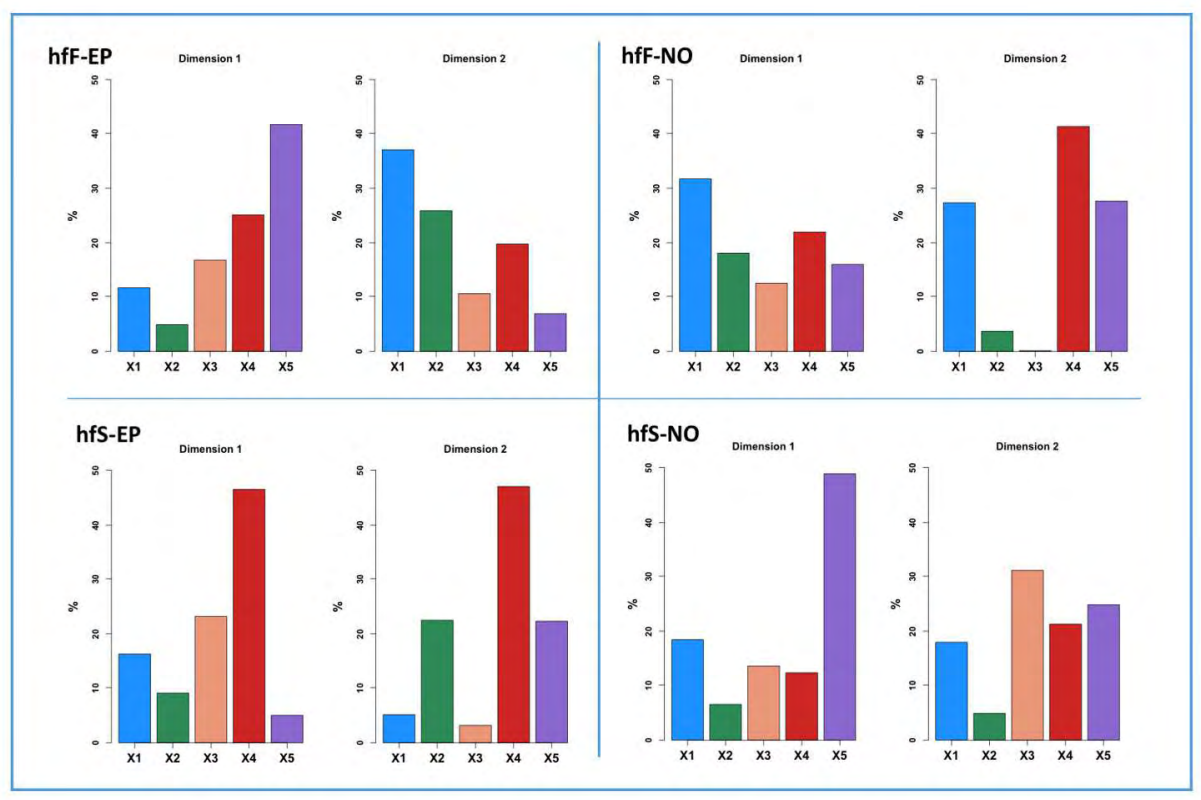

Figure 3. Bar charts representing the relative importance (\%) of the different blocks of variables (X1-X5) for the different components obtained by means of MB-PLS analysis performed on fruity aroma (EP) and blue cheese aroma (NO) sensory data set and for the high fat (hfF \& hfS) cheese products. Blue chart: X1-Aroma release, Green chart: X2-rheology, Orange chart: X3-coating and oral volume, Red chart: X4-EM data, Violet chart: X5-stimulated saliva composition. 


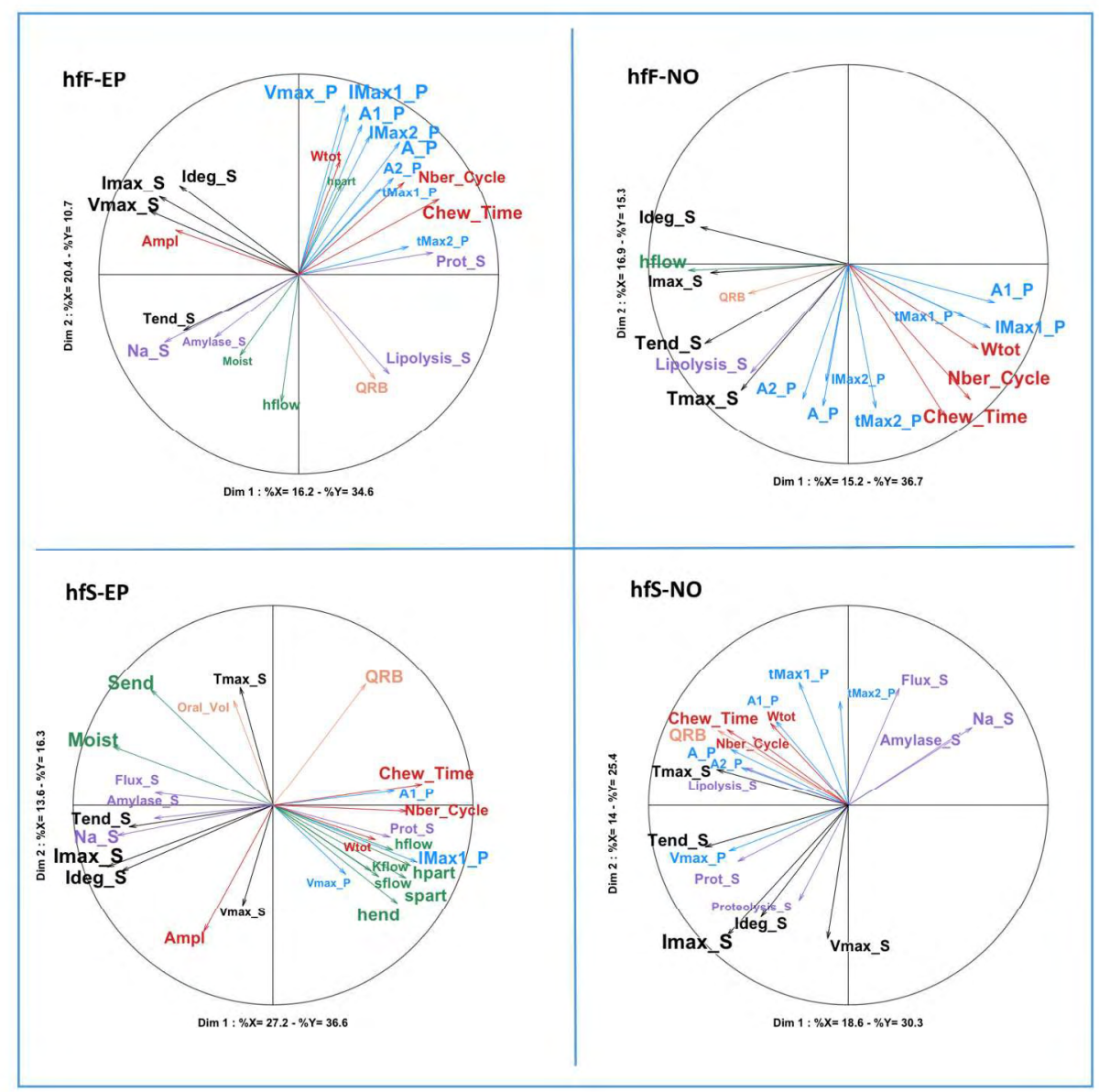

Figure 4. MB-PLS results on $\operatorname{dim} 1 / \operatorname{dim} 2$ for high fat (hf) cheeses: relationships between the $X$-blocks of explanatory variables (Blue arrows: X1-aroma release, Green arrows: X2-rheology, Orange arrows: X3coating and oral volume, Red arrows: X4-EMG data, Violet arrows: X5-stimulated saliva composition) and the $Y$ block of variables to be explained (Black arrows: sensory data for fruity aroma (EP) and blue cheese aroma (NO). Top: firm high fat cheeses (hfF), bottom: soft high fat cheeses (hfS). The font size for each variable reflects the importance of the correlation coefficient with the two components. 


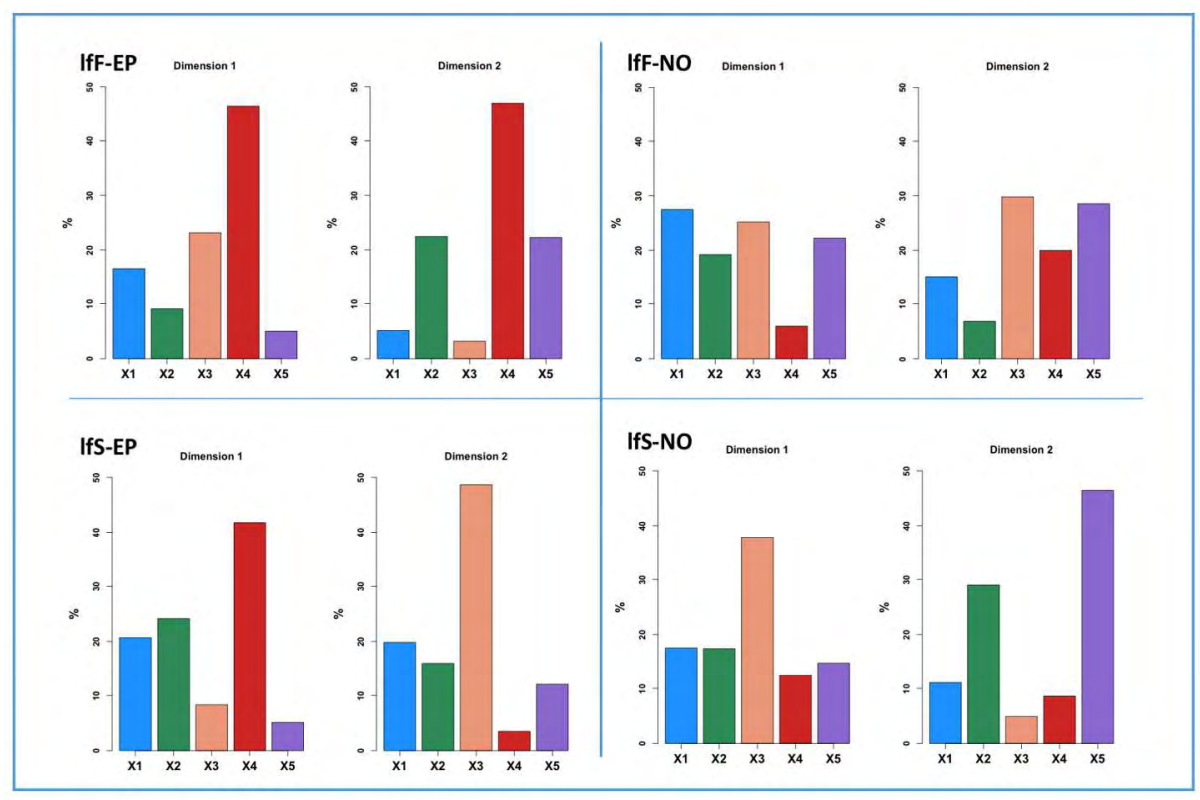

Figure 5. Bar charts representing the relative importance (\%) of the different blocks of variables (X1-X5) for the different components obtained by means of MB-PLS analysis performed on fruity aroma (EP) and blue cheese aroma (NO) sensory data set and for the low fat (IfF \& IfS) cheese products. Blue chart: X1-Aroma release, Green chart: X2-rheology, Orange chart: X3-coating and oral volume, Red chart: X4-EM data, Violet chart: X5-stimulated saliva composition.

$$
705 \times 448 \mathrm{~mm}(72 \times 72 \text { DPI })
$$




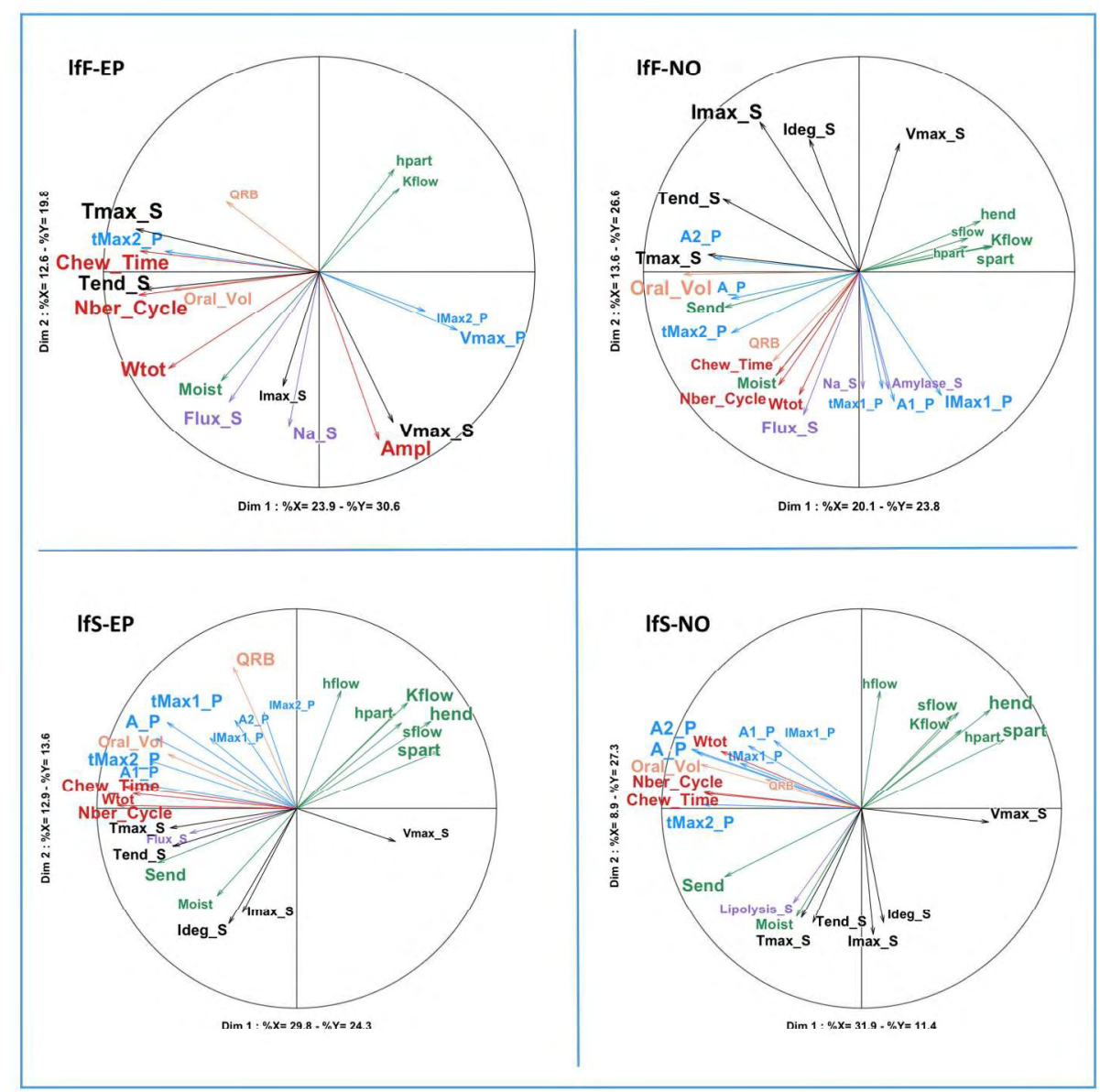

Figure 6. MB-PLS results on $\operatorname{dim} 1 / \operatorname{dim} 2$ for low fat (If) cheeses: relationships between the $X$-blocks of explanatory variables (Blue arrows: X1-aroma release, Green arrows: X2-rheology, Orange arrows: X3coating and oral volume, Red arrows: X4-EMG data, Violet arrows: X5-stimulated saliva composition) and the $Y$ block of variables to be explained (Black arrows: sensory data for fruity aroma (EP) and blue cheese aroma (NO). Top: firm low fat cheeses (IfF), bottom: soft low fat cheeses (IfS). The font size for each variable reflects the importance of the correlation coefficient with the two components. 